\title{
MINERAÇÃO E GEOCONSERVAÇÃO: O SÍTIO PALEONTOLÓGICO DE SANTA ROSA DE VITERBO, SP
}

\author{
Ana Lúcia Desenzi GESICKI \\ Rodrigo Miloni SANTUCCI
}

\begin{abstract}
RESUMO
Os depósitos fossilíferos são bens da União e cabe ao Departamento Nacional de Produção Mineral - DNPM fiscalizar sua extração em território nacional, assim como garantir medidas de proteção do patrimônio paleontológico e o combate à extração ilegal de fósseis. Cabe também ao órgão mediar conflitos entre a produção legalizada de bens minerais e a proteção de depósitos fossíliferos de relevante valor científico ou cultural. Com este objetivo, a Diretoria de Fiscalização do DNPM implantou um programa de fiscalização no Estado de São Paulo com o intuito de diagnosticar áreas de mineração em situação de conflito com a preservação de depósitos fossilíferos já conhecidos pela comunidade geocientífica. Este diagnóstico priorizou a fiscalização de minerações de calcário do interior do estado com aproveitamento de rochas permianas do Subgrupo Irati (Bacia do Paraná), devido à ocorrência de fósseis de mesossauros, invertebrados e icnofósseis. Não foram identificados conflitos significativos nas áreas vistoriadas, exceto em uma mina de Santa Rosa de Viterbo, devido à ocorrência de estromatólitos dômicos de dimensões métricas cujo depósito é diretamente lavrado pela empresa mineradora para a produção de corretivo de solo. Os depósitos estromatolíticos do Subgrupo Irati que afloram nesta mina correspondem às únicas ocorrências conhecidas da Bacia do Paraná e também são raros em relação aos depósitos calcários do Fanerozóico em geral. Diante da necessidade de garantir medidas efetivas de conservação de sítio fossilífero tão raro, o DNPM/SP providenciou a interdição de uma área de $680 \mathrm{~m}^{2}$, localizada em uma porção inoperante da área de concessão, onde foram garantidas exposições representativas do depósito, segurança em relação às operações de lavra e facilidade de acesso. Esta iniciativa demonstra que é viável implantar medidas de geoconservação dentro de áreas de mineração e que se deve buscar a articulação entre o poder público, o segmento produtivo e a comunidade geocientífica.
\end{abstract}

Palavras-chave: patrimônio paleontológico, estromatólito, mineração, calcário.

\section{ABSTRACT}

Fossiliferous deposits are assets of the Union, and the DNPM (National Department of Mineral Production) is responsible for controlling their extraction in the country, for providing means to ensure that the paleontological heritage is protected, and for preventing illegal collection of fossils. The DNPM also resolves conflicts between the legal extraction of mineral resources and the protection of fossils of great scientific or cultural value. With this objective in mind, the Inspection Board of DNPM implemented a monitoring program in São Paulo State for identifying areas where mining is in conflict with the preservation of the fossils already known by the geoscientific community. This program prioritized the inspection of limestone quarries in São Paulo State where Permian rocks of the Irati Subgroup (Paraná Basin) are mined. These fossil deposits are of scientific interest and educational relevance due to the presence of mesosaurus, invertebrates and trace fossils. The inspection found no significant conflict between extraction activity and fossil preservation, although in the Santa Rosa de Viterbo quarry, an exceptional situation in relation to other quarries was found: the occurrence of well-preserved domal stromatolites of metric sizes, whose deposit is being mined for soil corrective. The Permian 
stromatolitic deposits that outcrop in the Santa Rosa de Viterbo quarry are the only known occurrences of the Paraná Basin and are also rare when compared to other world Phanerozoic calcareous deposits. Faced with the need to ensure that the site where these rare fossils have been found is effectively preserved, the DNPM imposed a ban on mining in an area of about $680 \mathrm{~m}^{2}$ located in a inactive part of the concession area, preserving representative exposures of the deposit, protecting the area against mining operations, and allowing easy access to the preserved area. This demonstrates that geoconservation initiatives are feasible in mining areas and that cooperation among government, mining sector and geoscientific community should be sought.

Keywords: paleontological heritage, stromatolite, mining, limestone.

\section{INTRODUÇÃO}

Práticas de conservação dos elementos geológicos da natureza - ou geoconservação - estão em aparente contínuo conflito com a mineração: a primeira é em geral preservacionista e a segunda necessariamente modificadora do meio original. Seriam, em princípio, práticas mutuamente excludentes, mas que podem ser conciliadas.

Um exemplo comumente empregado é o Geoparque Arouca, em Portugal, onde já existia uma mineração de ardósia para uso como revestimento. Lá foi descoberto e posteriormente preservado um sítio paleontológico com ocorrência de exemplares excepcionais de trilobites paleozóicos gigantes (GUTIÉRREZ-MARCO et al. 2009), no qual tem sido possível preservar os fósseis e dar continuidade à lavra. Sem a lavra seria praticamente impossível realizar os estudos paleontológicos ali desenvolvidos.

No Brasil, são raros ainda os exemplos que conciliam a mineração e a geoconservação, sendo assim, este trabalho tem por objetivo discutir o caso do sítio paleontológico de Santa Rosa de Viterbo, em São Paulo.

Infelizmente a mineração é ainda bastante estigmatizada por ser uma atividade potencialmente degradadora do meio ambiente. A sociedade tem uma visão negativa dos empreendimentos mineiros, pois não é devidamente esclarecido que o uso de bens minerais advindos da mineração está diretamente ligado à manutenção da sua qualidade de vida. Em vista do ritmo acelerado de crescimento da população mundial é natural que cresça a pressão sobre o aproveitamento dos recursos minerais e aumente, na mesma proporção, a pressão por medidas de proteção e conservação dos recursos naturais. Crescimento econômico e conservação já disputam atualmente os mesmos territórios e ambas realidades são irreversíveis. No caso dos recursos minerais, cabe principalmente à comunidade geológica e ao poder público mediar este conflito, para garantir que o aproveitamento racional e eficiente desses recursos seja compatível com a manutenção de práticas de conservação do meio natural, atendendo à legislação vigente e às necessidades da sociedade moderna.

O Departamento Nacional de Produção Mineral (DNPM) é o órgão responsável pela autorização e fiscalização da extração de espécimes fósseis em território nacional (Decreto-Lei ${ }^{\circ}$ 4.146/1942). Ao mesmo tempo, tem por atribuição gerir e fomentar o aproveitamento econômico dos recursos minerais da União, segundo os dispositivos do Código de Mineração (Decreto-Lei $\mathrm{n}^{\circ}$ 227/1967) e legislação correlata. Este cenário revela algumas situações práticas em que o órgão precisa mediar conflitos de interesse, como no caso de ocorrências fossilíferas em áreas de mineração.

Este artigo é dividido em duas partes, na primeira há um histórico e uma abordagem conceitual e legal a respeito da geoconservação e da proteção do patrimônio geológico e paleontológico no Brasil; a segunda refere-se a um estudo de caso de proteção de um sítio paleontológico em uma área de mineração ativa de calcário em Santa Rosa de Viterbo, interior do Estado de São Paulo, realizada por iniciativa do DNPM/SP. O objetivo deste trabalho é demonstrar ser viável a implantação de medidas de geoconservação em áreas onde a mineração está em plena atividade.

\section{INICIATIVAS DE GEOCONSERVAÇÃO NO BRASIL}

Os primeiros registros legais de conservação da natureza no Brasil são da década de 1930, com a promulgação do Código Florestal de 1934 (Decreto $\mathrm{N}^{\circ} 23.793$ de 23/01/1934), o qual foi posteriormente reformulado pela Lei $\mathrm{N}^{\circ} 4.771$ de 15/09/1965, que 
está em revisão no Congresso Nacional. Ações direcionadas à criação de áreas protegidas no Brasil, tais como parques nacionais e estaduais, revelam uma preocupação precoce do poder público com a conservação da natureza. Exemplos desta natureza foram a criação do Parque Nacional do Itatiaia (RJ) em 1937, Parque Nacional da Serra dos Órgãos (RJ) em 1939, Parque Estadual Turístico do Alto Ribeira (SP) em 1958 e outros que se sucederam. Junta-se também a legislação direcionada à proteção do patrimônio histórico e artístico nacional, conhecida como Lei do Tombamento, promulgada pelo Decreto-Lei No 25 de 30/11/1937.

A partir da década de 1980, em consonância com os novos princípios propalados pela conscientização ambientalista ao redor do mundo, o Brasil também fincou um novo marco legal para a proteção do meio ambiente promulgando a Lei $\mathrm{N}^{\mathrm{o}} 6.938$ de 31/08/1981, que instituiu a Política Nacional de Meio Ambiente (PNMA). Dentre os diversos objetivos da PNMA, o inciso VI do seu Art. $4^{\circ}$ visa à "preservação e restauração dos recursos ambientais com vistas à sua utilização racional e disponibilidade permanente, concorrendo para a manutenção do equilíbrio ecológico propício à vida"

Outra importante ferramenta de conservação da diversidade biológica brasileira é a Lei № 9.985 de 18/07/2000, que instituiu o Sistema Nacional de Unidades de Conservação - SNUC para sistematizar normas e critérios para a criação, implantação e gestão de áreas protegidas.

O Brasil também é signatário de duas importantes convenções internacionais realizadas no início da década de 1970 pela Organização das Nações Unidas para a Educação, a Ciência e a Cultura - UNESCO para incentivar a cooperação internacional e criação de protocolos de intenções voltados à conservação da natureza e proteção do patrimônio cultural.

Na Convenção de 1970 foi elaborado um texto "sobre as Medidas a serem Adotadas para Proibir e Impedir a Importação, Exportação e Transferência de Propriedade Ilícitas dos Bens Culturais", enquanto que na Convenção de 1972 tratou-se, pela primeira vez, das iniciativas de cooperação internacional para a proteção do Patrimônio Mundial, Cultural e Natural.

Na Convenção da UNESCO de 1972 instituiu-se o Comitê do Patrimônio Mundial (World Heritage Committee - WHC) para acolher propostas de candidatos a patrimônio da humanidade. Sob os auspícios dos países membros signatários desta Convenção foi organizado, a partir de 1989, um in- ventário mundial de sítios geológicos, denominado GILGES (Global Indicative List of Geological Sites) que, em 1996, foi substituído pela base de dados global GEOSITE (Database on Geological Sites), coordenada pela IUGS (International Union of Geological Sciences).

Com o objetivo de efetivar a participação brasileira no inventário mundial de sítios geológicos, o Departamento Nacional de Produção Mineral - DNPM articulou a criação, em 1997, da Comissão Brasileira de Sítios Geológicos e Paleobiológicos - SIGEP (SCHOBBENHAUS et al. 2002). Esta comissão é constituída por representantes de diversas instituições públicas e associações científicas que atuam na área das Geociências e tem por objetivo receber e avaliar propostas de áreas com características geológicas excepcionais, candidatas à categoria de geossítios, encaminhadas por qualquer interessado da comunidade geológica. Após 14 anos de existência, a SIGEP conta com mais de uma centena de propostas aprovadas, representativas de vários estados do Brasil e de distintos contextos geológico, paleontológico, estratigráfico, ígneo, geomorfológico, entre outros. Os artigos completos dos geossítios publicados encontram-se disponíveis na Internet (http://sigep.cprm.gov.br), em dois volumes impressos (SCHOBBENHAUS et al. 2002; WINGE et al. 2009) e ainda um terceiro volume, no prelo, com capítulos disponíveis em versões pre print na página da SIGEP.

A conservação da natureza no Brasil possui viés voltado prioritariamente à conservação da biodiversidade e, muitas vezes, emprega-se um como sinônimo do outro. No entanto, os recursos naturais compreendem, além dos elementos bióticos, elementos do meio físico que são também dotados de valor intrínseco, compondo a geodiversidade (BRILHA 2005). São recentes os esforços empenhados para inventariar e proteger a geodiversidade, à semelhança daquele dado em nível mundial à conservação da biodiversidade. No Brasil, estes esforços estão materializados em diversas iniciativas, com destaque à da SIGEP, descrita anteriormente, e de algumas instituições estaduais de geologia e mineração como, por exemplo, o Departamento de Recursos Minerais do Rio de Janeiro (DRM/RJ), por meio do projeto Caminhos Geológicos (http:// www.caminhosgeologicos.rj.gov.br), e o Instituto Geológico de São Paulo (IG/SMA/SP), que preside o Conselho Estadual de Monumentos Geológicos de São Paulo (CoMGeo-SP).

Conforme apontado por BRILHA (2005), a prática de identificar e inventariar a geodiversidade é essencial para o reconhecimento dos elemen- 
tos dotados de qualquer valor superlativo, seja ele científico, cultural, recreativo ou outro. Os elementos dotados de valor superlativo, delimitados geograficamente - os geossítios - compõem, portanto, o patrimônio geológico de uma região, aos quais devem ser voltados os esforços prioritários de conservação, ou de geoconservação. No sentido amplo, BRILHA (2005) defende que as estratégias de geoconservação têm como objetivo a utilização e gestão sustentável de toda a geodiversidade.

2.1 O SNUC, a Lei do Tombamento e o conceito de Geoparque

Existem vários exemplos de proteção e conservação dos elementos da geodiversidade brasileira devido à criação de unidades de conservação e à implantação de áreas tombadas. Se no primeiro caso o foco geralmente é voltado aos elementos da biodiversidade, no segundo é direcionado aos elementos da paisagem ou de apelo cultural. Citam-se os exemplos do Parque Nacional de Fernando de Noronha, em Pernambuco, o Parque Nacional da Chapada dos Veadeiros, em Goiás, as Gruta do Lago Azul e Nossa Sra. Aparecida, em Mato Grosso do Sul, estas últimas tombadas pelo IPHAN (Instituto do Patrimônio Histórico e Artístico Nacional). Estas unidades destacam-se pelos seus aspectos litológicos e geomorfológicos, de grande beleza cênica e forte apelo turístico.

A proteção da paisagem natural insere-se tanto nos objetivos do Sistema Nacional de Unidades de Conservação - SNUC (inciso VI do Art. $4^{\circ}$ da Lei 9.985/2000), quanto na lei de Tombamento ( $\$ 2^{\circ}$ do Art. $1^{\circ}$ do Decreto-Lei № 25/1937).

O Artigo $4^{\circ}$, incisos VII e VIII da Lei do SNUC, prevê também a proteção de elementos da geodiversidade, ao contemplar as características relevantes de natureza geológica, geomorfológica, espeleológica, arqueológica, paleontológica e cultural, além dos recursos hídricos e edáficos. $\mathrm{Na}$ prática, porém, o mote principal para criação de unidades de conservação é o apelo à proteção de biomas ameaçados pelo ser humano.

As categorias atribuídas às áreas protegidas pelo SNUC estão divididas em dois grandes grupos: as unidades de proteção integral e as unidades de uso sustentável. A mineração é uma atividade econômica incompatível com os objetivos preservacionistas das unidades de proteção integral, uma vez que só é permitido o uso indireto de seus recursos naturais. Esta atividade pode ser desenvolvida dentro das unidades de conservação de uso sustentável (exceto reserva extrativista), desde que seja possível compatibilizar a mineração com a conservação dos recursos naturais e se observe as diretrizes e eventuais restrições estabelecidas no plano de manejo da unidade.

O processo de tombamento do meio natural é uma importante ferramenta de proteção do patrimônio geológico, onde o componente paleontológico se destaca (DELPHIM 2009), tendo em vista o valor cultural que a Constituição Federal de 1988 atribui aos sítios fossilíferos. Os efeitos de um tombamento impõem às áreas tombadas e suas vizinhanças severas restrições a qualquer tipo de intervenção (Art. 17 do Decreto-Lei № 25/1937). Cita-se o exemplo do Parque do Varvito, em Itu, onde uma antiga área de lavra foi definitivamente paralisada por ter sido tombada pelo órgão estadual de proteção do patrimônio.

O conceito de Geoparque, difundido pela UNESCO a partir do ano de 1997, surgiu como uma alternativa para a geoconservação. O Geoparque é uma área geográfica bem definida, com patrimônio geológico singular, onde se implantam estratégias de desenvolvimento sustentável das populações locais combinadas à proteção deste patrimônio (ZOUROS 2004). Dentro de um geoparque são incentivados o geoturismo, a divulgação e a pesquisa científica, a educação ambiental e o resgate da cultura e dos costumes locais.

Não há uma única forma de implantar tais estratégias de desenvolvimento sustentável para a criação de um geoparque, mas destaca-se a importância da participação das populações locais e o apoio efetivo do poder público dentre os princípios preconizados pela UNESCO (2008). O conceito de geoparque teve uma grande aceitação ao longo da última década e rapidamente foram criados dezenas de geoparques em diversos países da Europa e Ásia, por meio de redes de cooperação internacional.

Neste contexto, uma parcela importante de sítios paleontológicos da Bacia do Araripe foi delimitada pelo Governo do Estado do Ceará para compor o Geopark Araripe, criado em 2006 sob a chancela da UNESCO (HERZOG et al. 2008). Trata-se do único geoparque das Américas membro da Rede Global de Geoparques. Este novo conceito de geoconservação encontra-se em expansão no Brasil e envolve iniciativas de entidades como o Serviço Geológico do Brasil - CPRM, o IPHAN e universidades públicas, que submeteram, recentemente, dossiês de candidatura à Rede Global de Geparques das propostas de Geoparque do Quadrilátero Ferrífero e Geoparque Bodoquena-Pantanal (SCHOBBENHAUS \& SILVA 2010). 
2.2 Aspectos legais sobre a proteção dos depósitos fossilíferos

O Decreto-Lei No 4.146 de 04/03/1942 preconiza que os depósitos fossilíferos são propriedade da Nação e que a extração de espécimes fósseis depende de autorização prévia e fiscalização do Departamento Nacional de Produção Mineral - DNPM. Embora a extração de fósseis deva ser formalmente autorizada pelo DNPM, independem desta autorização e fiscalização a coleta de fósseis para fins de pesquisa científica, realizada por pesquisadores de museus nacionais ou estaduais e de instituições congêneres (universidades e institutos de pesquisa). Os pesquisadores precisam apenas comunicar o DNPM previamente à realização de coletas para fins científicos.

A Constituição Federal de 1988 reforçou o caráter de bem público dos depósitos fossilíferos no Art. 20, inciso I, e ainda considerou os "sítios de valor paleontológico" como patrimônio cultural da União (inciso V do Art. 216). Segundo o texto constitucional, é de competência do poder público, com a colaboração da comunidade, "promover e proteger o patrimônio cultural brasileiro por meio de inventários, registros, vigilância, tombamento e desapropriação, e outras formas legais vigentes de acautelamento e preservação" ( $\left(1^{\circ}\right.$ do Art. 216 da CF).

Fundamentado nas diretrizes estabelecidas pela Convenção da UNESCO de 1970, da qual o Brasil é signatário, os países se comprometeram a instituir medidas legais de combate à importação, exportação e transferência de propriedade ilícita de bens culturais, incluindo neste grupo os fósseis e os artefatos arqueológicos, de forma a proteger este patrimônio. No Brasil, o texto da Convenção foi aprovado pelo Decreto Legislativo $N^{\circ} 71 / 1972$ e posteriormente promulgado pelo Decreto $\mathrm{N}^{\circ}$ 72.312 de 31/05/1973.

Em consonância às diretrizes da Convenção de 1970, o DNPM é o órgão anuente desde 2006 das transações internacionais referentes à exportação de espécimes fósseis. A saída de material fossilífero do território nacional depende de sua prévia autorização junto ao Sistema Integrado de Comércio Exterior (SISCOMEX) do Ministério de Desenvolvimento, Indústria e Comércio Exterior MDIC, utilizando-se da Nomenclatura Comum do Mercosul - NCM 9705.00.00, destaque $\mathrm{n}^{\circ} 04$.

Considerando ainda que o Decreto-Lei $\mathrm{N}^{\circ}$ 4.146/1942 não trata especificamente do comércio de fósseis e pelo fato de não existir uma regulamentação sobre o assunto no Brasil, a extração de fósseis em todo o território nacional com objetivo comercial (venda) não é autorizada pelo DNPM, tendo em vista os dispositivos constitucionais que lhes asseguram um valor cultural. No lado oposto, estão países como EUA, Alemanha, Japão e Inglaterra, que possuem legislação favorável ao comércio de fósseis nos seus territórios e que não assinaram o texto da Convenção de 1970.

Assim, compete ao DNPM a fiscalização da extração de fósseis no país, com o objetivo de garantir a proteção dos depósitos fossilíferos e o combate à extração ilegal. A gestão operacional de fiscalização do patrimônio paleontológico está a cargo da Diretoria de Fiscalização do DNPM e das divisões homônimas das unidades da autarquia descentralizadas nos estados (superintendências). No âmbito da Diretoria de Fiscalização, existe uma Divisão de Proteção dos Depósitos Fossiliferos, à qual compete coordenar e supervisionar as ações de fiscalização em conjunto com os órgãos descentralizados nos estados. Os procedimentos internos quanto às práticas de fiscalização e proteção destes depósitos, embora ainda em discussão no âmbito de Diretoria, envolvem o salvamento e a apreensão de exemplares fósseis, assim como a adoção de medidas de proteção de depósitos fossilíferos e dos sítios paleontológicos reconhecidos pela comunidade científica, quando necessário.

O DNPM dispõe de uma ferramenta administrativa para a proteção de depósitos fossilíferos baseada nos dispositivos das Normas Reguladoras de Mineração (NRM), instituídas pelas portarias DNPM No 237 de 18/10/2001 e DNPM No 12 de $22 / 01 / 2002$. Segundo a NRM 1.5.12, cabe interdição da área de lavra em caso de ocorrência de fósseis ou materiais de interesse arqueológico, até a análise e manifestação do DNPM. No entanto, a aplicação desse procedimento restringe-se às áreas tituladas $\mathrm{e}$ aos concessionários de direitos minerários.

Em vista dos mecanismos legais vigentes de proteção do patrimônio histórico e cultural em nível federal e estadual, cuja aplicação compete, respectivamente, ao IPHAN e aos órgãos congêneres estaduais (ex. o Condephaat, em São Paulo) e até municipais, abre-se o leque de ações compartilhadas voltadas à proteção do patrimônio paleontológico por meio do tombamento (DELPHIM 2009), muito raramente estabelecidas atualmente.

\section{A FISCALIZAÇÃO DOS DEPÓSITOS FOSSILÍFEROS EM SÃO PAULO}

A partir de 2006, com a ampliação do seu corpo técnico de paleontólogos e geólogos, o DNPM iniciou programa sistemático de fiscalização de de- 
pósitos fossilíferos em diversos estados brasileiros, visando, sobretudo, a gestão e proteção deste patrimônio. Grande parte das ações fiscalizadoras foi e ainda é motivada por demandas externas, como denúncias e requisições da Justiça, como o Ministério Público Federal, Ministério Público Estadual e Polícia Federal.

O programa de fiscalização dos empreendimentos de mineração no Estado de São Paulo, voltado ao combate à extração ilegal de fósseis, foi iniciado em janeiro de 2007, provocado por uma reportagem publicada no jornal Folha de São Paulo (caderno Ciência de 03/01/2007) sobre a apreensão de exemplares fósseis de mesossauros realizada pela Aduana Francesa em 07/11/2006 (disponível em http://www.douane.gouv.fr/page.asp?id=565 ). Os fósseis em excepcional estado de preservação foram avaliados em $€ \$ 100$ mil e teriam sido extraídos ilegalmente de uma mineração de calcário na região de Angatuba, SP.

A Diretoria de Fiscalização do DNPM determinou a realização de cinco campanhas de fiscalização no período de 2007-2008 nas empresas que aproveitam o calcário do Subgrupo Irati, localizadas nas regiões de Angatuba, Itaí, Itapetininga, Rio Claro, Saltinho, Piracicaba, Ipeúna, Laranjal Paulista, Tietê, Pereiras e Santa Rosa de Viterbo. Após vistoria na mineração objeto da reportagem, constatou-se que ela não possuia autorização do DNPM para a extração de calcário ou de fósseis e, consequentemente, o titular foi autuado.

As campanhas de vistoria foram executadas com o objetivo de diagnosticar material paleontológico nas áreas de lavra de calcário do Subgrupo Irati (Permiano Superior da Bacia do Paraná) no Estado de São Paulo, visando identificar eventual situação de incompatibilidade entre a mineração e a preservação de sítios fossilíferos e combater a prática de extração não autorizada de fósseis. Esses trabalhos também enfatizaram o salvamento e a amostragem de exemplares fósseis, o reconhecimento de fácies carbonáticas com implicações paleoambientais específicas para o processo de fossilização, a conscientização dos trabalhadores da mineração sobre a importância científica dos fósseis paleozóicos e a ilegalidade do seu comércio, além da identificação de áreas potenciais para preservação.

Foram vistoriadas aproximadamente $25 \mathrm{mi}-$ nerações de calcário dolomítico no interior paulista, com aproveitamento de rochas do Subgrupo Irati. Apesar dos fósseis de vertebrados, invertebrados e icnofósseis (Figura 1) serem muito comuns nas rochas do Subgrupo Irati, são raras as ocorrências de exemplares fósseis relevantes, como esqueletos inteiros articulados e bem preservados de mesossauros, vertebrado característico desta unidade estratigráfica.

Os poucos exemplares fósseis salvos durante as campanhas de campo prestam-se mais para fins didáticos do que à pesquisa científica, visto que eles constituem, em sua maioria, fragmentos de ossos desarticulados. Até o momento, não houve um fato que justificasse a paralisação ou o impedimento da lavra de calcário devido à ocorrência deste material fóssil.

Ressalta-se que em virtude da dinâmica das áreas de mineração, as frentes de lavra ativas de uma mina são os locais mais propícios a novas descobertas paleontológicas. Uma das recomendações do programa de fiscalização é o monitoramento periódico das minas pelo setor de fiscalização do DNPM e com a colaboração de pesquisadores de universidades e de instituições de pesquisa, observando-se a lei, para garantir medidas de salvamento de exemplares fósseis relevantes.

Há um entendimento jurídico recente no DNPM, emanado pela Procuradoria Geral da Autarquia, por meio do Parecer No 107/2010/PROGE, de que existe uma distinção implícita no Código de Mineração sobre o regime jurídico de acesso aos fósseis em função da sua destinação (DNPM 2010). O inciso III do Art. 10 do Código de Mineração prevê que "os espécimes minerais ou fósseis destinados a Museus, Estabelecimentos de Ensino e outros fins científicos" são regidos por legislação específica, neste caso, o Decreto-Lei $\mathrm{N}^{\circ}$ 4.146/1942. Assim, os espécimes fósseis não enquadrados no referido artigo submetem-se ao regime jurídico de recurso mineral, sujeitando-se ao regramento do Código de Mineração (item 42, Parecer No 107/2010/PROGE). Obviamente, a ausência de normas infralegais na área de Paleontologia não permite generalizações para que esta interpretação jurídica abra espaço para o aproveitamento comercial de fósseis ou de depósitos fossilíferos. Por outro lado, há segurança jurídica ao DNPM e aos seus administrados de que a atividade de mineração não será paralisada ou inviabilizada devido a ocorrências pontuais de fósseis irrelevantes do ponto de vista científico ou didático.

\subsection{O Sítio Paleontológico de Santa Rosa de Viterbo}

O município de Santa Rosa de Viterbo está localizado no nordeste do Estado de São Paulo, distante cerca de $300 \mathrm{~km}$ da capital e $60 \mathrm{~km}$ da cidade de Ribeirão Preto, cujo acesso é feito pela 

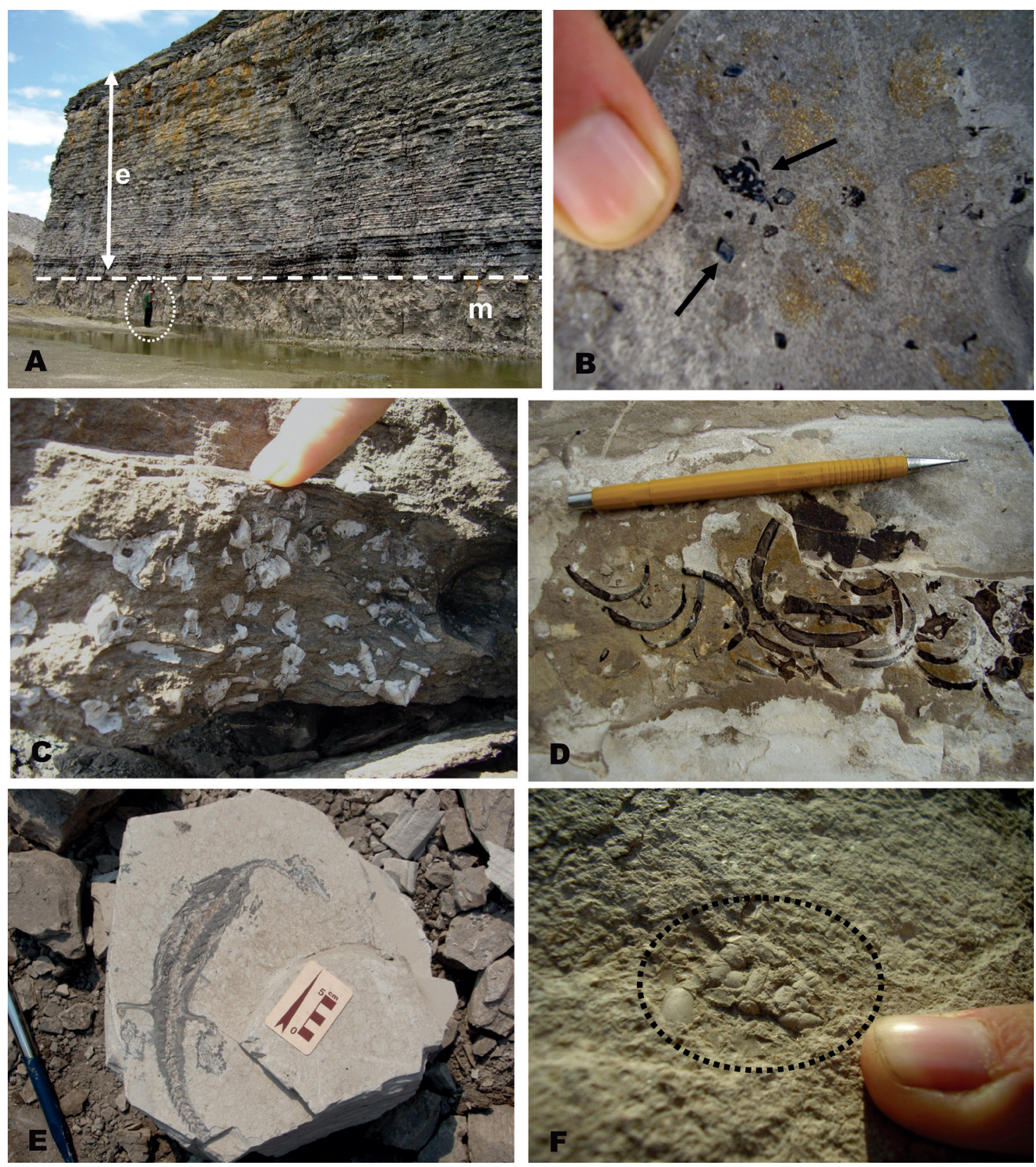

FIGURA 1 -Fósseis em rochas do Subgrupo Irati no interior paulista. A: Exposição típica das rochas da Formação Assistência nas frentes de lavra da região de Rio Claro. O minério (m), que constitui a camada inferior, possui $2 \mathrm{~m}$ de espessura média de calcário magnesiano. A porção estéril (e) sobrejacente, composta de ritmitos, possui até $15 \mathrm{~m}$ de espessura. B: escamas de peixes (setas). C, D: camada com concentração de fragmentos de ossos de mesossaurídeos (bonebed). E: exemplar articulado de mesossaurídeo. F: carapaças de crustáceos.

rodovia SP330 (Rodovia Anhanguera) e rodovia SP253. Afloram nesta região rochas sedimentares paleozóicas e mesozóicas da Bacia do Paraná, com exposições do Subgrupo Irati e das formações Corumbataí, Pirambóia e Botucatu. As rochas calcárias dolomíticas do Subgrupo Irati, em função da sua composição magnesiana, são mineradas desde a década de 1970 para a produção de corretivo de solo por uma única empresa sediada no município, a PH7 Mineração de Calcário Ltda.

O Subgrupo Irati é uma unidade estratigráfica não muito espessa (em média $70 \mathrm{~m}$ ), conside- 
rada como datum da Bacia do Paraná, em virtude de sua homogeneidade faciológica, seu conteúdo fossilífero e pela ampla área de ocorrência. É composta por litotipos diversos como calcários dolomíticos, margas, folhelhos, folhelhos betuminosos e ritmitos, além de termos subordinados terrígenos (arenitos) e evaporíticos (anidrita). A estratigrafia da unidade Irati foi redefinida por HACHIRO (1996) no status de Subgrupo, individualizado em Formação Taquaral, inferior, essencialmente pelítica, e Formação Assistência, superior, composta por folhelhos, evaporitos, calcários e ritmitos.

HACHIRO (op. cit.) interpretou como estromatólitos as feições dômicas e colunares da camada de calcário dolomítico exposta na mina de Santa Rosa de Viterbo e associou-os à porção basal do Membro Ipeúna da Formação Assistência. Trata-se de um dos registros conhecidos de estromatólitos mais significativos da Bacia do Paraná e a presença destes fósseis indica condições de sedimentação carbonática desenvolvida em águas rasas e límpidas, provavelmente num contexto litorâneo influenciado por marés (HACHIRO \& COIMBRA 1992).

A ocorrência destes estromatólitos possui significado ímpar no registro geológico da Bacia do Paraná, uma vez que ela representa um tipo de depósito fossilífero com estruturas métricas raramente preservado em bacias sedimentares que evoluíram ao longo do Fanerozóico. Os estromatólitos são bioconstruções de organismos unicelulares microbianos (principalmente cianobactérias), na forma de esteiras e colunas, os quais eram as únicas formas de vida a povoar os oceanos primitivos; por este motivo constituem o registro fossilífero típico de unidades estratigráficas pré-cambrianas (KNOLL 1990). Após o evento conhecido como "explosão de vida cambriana", há aproximadamente $560 \mathrm{Ma}$, surgiram os organismos predadores ou perturbadores das esteiras microbianas, caracterizados por invertebrados metazoários e, consequentemente, decresce vertiginosamente o registro fossilífero de estromatólitos nas bacias marinhas (AWARAMIK 1971). A preservação de depósitos estromatolíticos nos oceanos paleozóicos ou mesmo nos modernos reflete condições ambientais bastante severas, tais como a alta salinidade, responsáveis por inibir a proliferação de qualquer organismo predador ou perturbador das bioconstruções (AWARAMIK $o p$. cit). É o caso dos depósitos de estromatólitos modernos de Shark Bay, na Austrália, onde as condições de hipersalinidade das águas marinhas favorecem somente a proliferação de esteiras microbianas.

Diante da relevância científica dos estromatólitos de Santa Rosa de Viterbo, RICARDI-BRANCO et. al. (2009) propuseram incluir uma área individualizada da mina para compor a lista de Sítio Paleontológico da SIGEP, com a proposta intitulada "Campo de estromatólitos gigantes de Santa Rosa de Viterbo, SP: excelente registro do litoral do mar permiano Irati, Bacia do Paraná, Brasil" (SIGEP No 125). Os autores da proposta do geossítio recomendaram que uma das frentes de lavra da mina, com aproximadamente $400 \mathrm{~m}$ de extensão, fosse preservada por apresentar a melhor exposição do nível de estromatólitos gigantes. Os autores deixaram claro que à época não havia nenhuma medida de proteção efetivamente implantada, pois a mineração encontrava-se em plena atividade, mas havia a predisposição do minerador em cooperar na realização de melhorias na área de exposição dos estromatólitos, como limpeza e isolamento da frente e construção de vias para o trânsito de pessoas.

3.2 Medidas de conservação: interdição parcial em área de concessão

A mina onde ocorrem os estromatólitos do Subgrupo Irati pertence à empresa PH7 Mineração de Calcário Ltda., que detém os direitos de lavra outorgados pelas Portarias MME No 1.370/1980, 268/1981e 481/1984 autorizativos da lavra de calcário para produção de corretivo de solo. As áreas de lavra foram vistoriadas por uma equipe de fiscais do DNPM em três oportunidades, em novembro e dezembro de 2007 e em outubro de 2008.

A lavra de calcário da empresa PH7 é executada a céu aberto com bancadas e desmonte por explosivos. A frente de lavra ativa à época das vistorias possuia aproximadamente $400 \mathrm{~m}$ de extensão e está localizada na porção norte de uma das poligonais que circunscrevem os direitos da empresa. As exposições das rochas do Subgrupo Irati na mina são representadas por uma camada de calcário dolomítico de $2 \mathrm{~m}$ de espessura média, com estromatólitos dômicos e colunares, os quais são recobertos por até $15 \mathrm{~m}$ de espessura de argilitos e siltitos laminados róseos e esverdeados da Formação Corumbataí. Diferentemente da sucessão de rochas verificada em outras minas de calcário do interior paulista, na de Santa Rosa de Viterbo não ocorrem os ritmitos (pares de camadas calcário-folhelho) e a camada de calcário dolomítico está 
sotoposta diretamente aos pelitos da Formação Corumbataí.

O banco de calcário dolomítico mostra uma associação de estromatólitos dômicos de dimensões métricas e com finas laminações internas, nos quais também se distinguem colunas com $5 \mathrm{~cm}$ de largura média dentro dos próprios domos maiores (Figura 2). Os domos possuem formato alongado na direção N40E do eixo maior e ostentam dimensões de até $3 \mathrm{~m}$ de altura por 1,5 $\mathrm{m}$ de largura. No topo dos domos/colunas e entre uma coluna e outra ocorrem concentrações pontuais de fragmentos de ossos de mesossauros que, em alguns casos, apre- sentam orientação preferencial paralela à orientação dos domos.

Concentração de escamas, dentes de peixes e coprólitos têm sido observados em alguns níveis da Formação Corumbataí. Os coprólitos variam de poucos milímetros até cinco centímetros de comprimento, podendo ser arredondados, alongados e até cilíndricos (Figura 2D).

A preocupação da equipe de fiscais do DNPM era conhecer as condições da mina (se em operação ou não) e verificar a possibilidade de preservação do sítio paleontológico. Uma enorme surpresa foi descobrir que o minério em aproveitamento era o
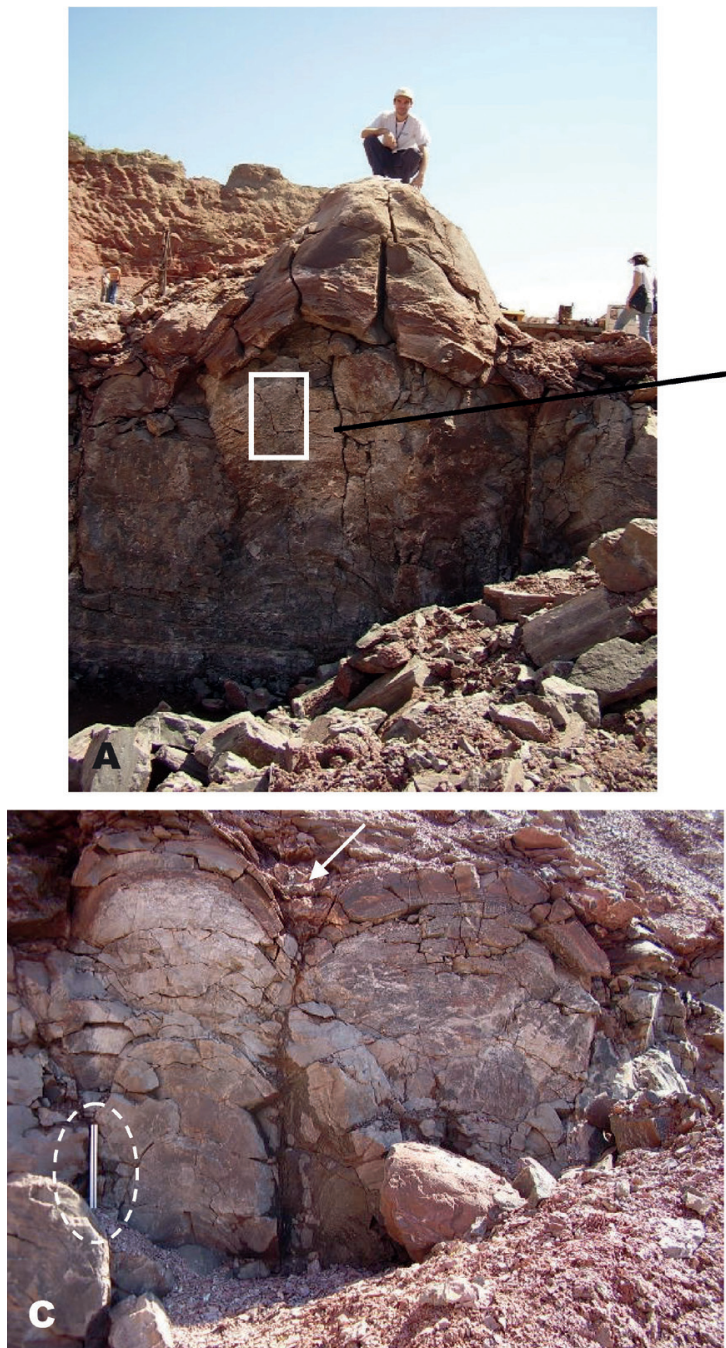
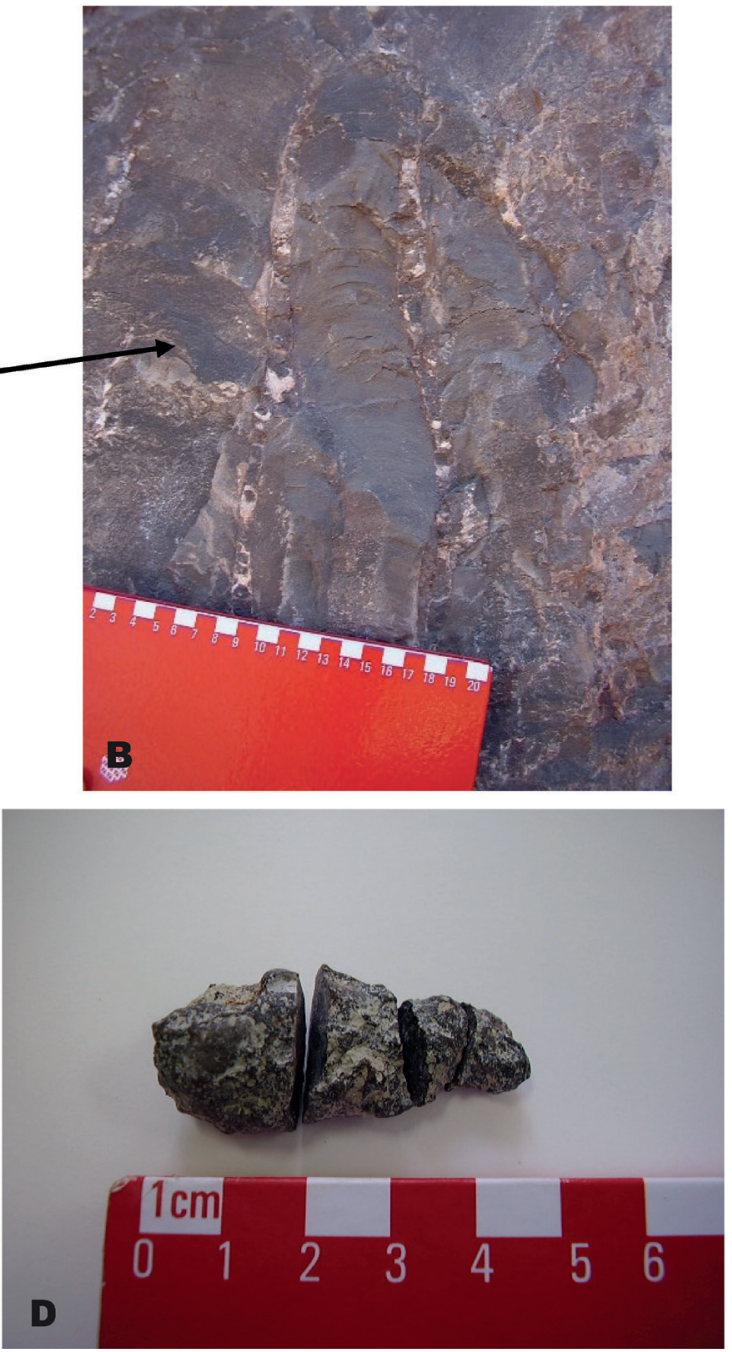

FIGURA 2 - Fósseis da mina de Santa Rosa de Viterbo, SP. A: Aspecto geral de estromatólito dômico gigante, com $3 \mathrm{~m}$ de altura. B: Detalhe de feições colunares com $4 \mathrm{~cm}$ de largura. C: Estromatólitos dômicos e fragmentos de ossos de mesossaurídeos (escala $=30 \mathrm{~cm}$ ) concentrados no espaço entre os domos (seta). D: Coprólitos da Formação Corumbataí. 
próprio corpo estromatolítico. Observou-se também que a área do sítio paleontológico proposto por RICARDI-BRANCO et al. (2009) não estava protegida, nem havia qualquer sinal que indicasse a demarcação dos seus limites, bem como qualquer ação de manutenção e preservação da frente de lavra com os estromatólitos.

Verificou-se ainda que a visualização das melhores estruturas estromatolíticas depende da orientação de corte das frentes de lavra. Nos cortes paralelos ao eixo maior dos domos, ou seja, na direção NE, as estruturas não são bem visíveis, enquanto que nos perpendiculares a este eixo (direção NW), as estruturas dômicas/colunares, padrões de ramificação das colunas e a estratificação interna são nítidos. A frente de lavra sugerida à SIGEP para proteção do sítio paleontológico seria $\mathrm{NE}$, mas nessa direção há fatores desfavoráveis quanto à visualização ideal dos estromatólitos e a questões de segurança, seja devido ao risco de desmoronamento do talude ou pela proximidade do corte às áreas de desmonte de calcário, onde há trânsito de máquinas pesadas e manipulação de explosivos.

Em novembro/2007, o DNPM providenciou a interdição temporária de uma frente de lavra inoperante da mina, como medida preliminar de proteção do sítio paleontológico, embora o corte não fosse muito favorável à visualização dos estromatólitos. Foram realizadas reuniões com a participação dos representantes da empresa e da proponente do sítio paleontológico (Prof ${ }^{\mathrm{a}}$ Frésia Ricardi-Branco), para, em visita conjunta às diversas frentes de lavra da concessionária, tratarem dos aspectos relacionados à escolha da área mais representativa dos estromatólitos, ponderando-se ainda a segurança, facilidade de acesso e posição em relação à cota de drenagem da área.

O local escolhido situa-se numa frente de lavra inoperante da mina (Figura 3), com fácil acesso por estrada municipal e protegido do trânsito de máquinas e veículos da mineração, onde o DNPM/SP lavrou novo Auto de Interdição (dezembro/2007), numa área de aproximadamente $680 \mathrm{~m}^{2}$, em substituição à anterior.

O minerador foi notificado pelo DNPM a demarcar o perímetro físico da área interditada e implantar melhorias no local: recuo e escalonamento da berma da frente de exposição de rochas para se evitar o desmoronamento da camada de siltitos sobreposta aos estromatólitos. Estas intervenções foram prontamente cumpridas pela empresa, a qual tomou a iniciativa de realizar outras melhorias por conta própria, como a construção de área de estacionamento, de um centro de atendimento ao visitante e de dois mirantes; instalação de escadas de ferro para acesso ao topo da camada de domos e também ao patamar superior, escavado nos siltitos da Formação Corumbataí (Figura 4). As melhorias já foram atendidas pela empresa mineradora e permitem não apenas uma visão tridimensional do depósito fossilífero, como também trouxeram mais atratividade, seja para a visitação e/ou para a investigação cientifica.

\section{CONCLUSÕES E RECOMENDAÇÕES}

Os depósitos fossilíferos são bens da União e cabe ao DNPM fiscalizar sua extração em território nacional. Pelo fato dos sítios de valor paleontológico possuírem atribuição constitucional como bens culturais, o DNPM entende que a proteção de depósitos fossilíferos de relevante interesse científico deve prevalecer sobre o interesse econômico. Portanto, cabe ao órgão mediar conflitos entre a produção legalizada de bens minerais e a proteção de depósitos fossíliferos de relevante valor científico ou cultural.

Com o objetivo de gerir o patrimônio fossilífero brasileiro, o DNPM tem empenhado esforços de fiscalização da mineração em conflito potencial com a preservação de sítios paleontológicos reconhecidos pela comunidade geocientífica. Neste sentido, foi realizada interdição em área de concessão de calcário dolomítico na região de Santa Rosa de Viterbo, SP, como medida de proteção de geossítio aprovado pela SIGEP, onde há ocorrência de campo de estromatólitos gigantes do Subgrupo Irati (Permiano da Bacia do Paraná). As atividades produtivas da empresa mineradora não foram paralisadas.

Cabe destacar que a mina de Santa Rosa de Viterbo recebe há muitos anos pesquisadores e estudantes de universidades paulistas com intuito didático. Uma vez que o geossítio está efetivamente protegido, abre-se a oportunidade de torná-lo um local de divulgação regional da Geologia e da Paleontologia.

Ressalta-se ainda que a importância do processo de conservação não está restrita à área interditada pelo DNPM. A efetiva implantação de projetos educacionais e de divulgação científica e uso das comunidades locais também são de fundamental importância para o sucesso da medida de geoconservação.

A título de recomendação, o DNPM deverá buscar sempre a articulação com outras instituições comprometidas com a geoconservação, seja na esfera federal, estadual ou municipal, e mediar, junto aos seus administrados, soluções consensuais que garantam a proteção do patrimônio paleontológico brasileiro. Uma parcela importante do sucesso deste tipo de iniciativa depende de medidas de bom senso e do envolvimento dos diversos setores inte- 

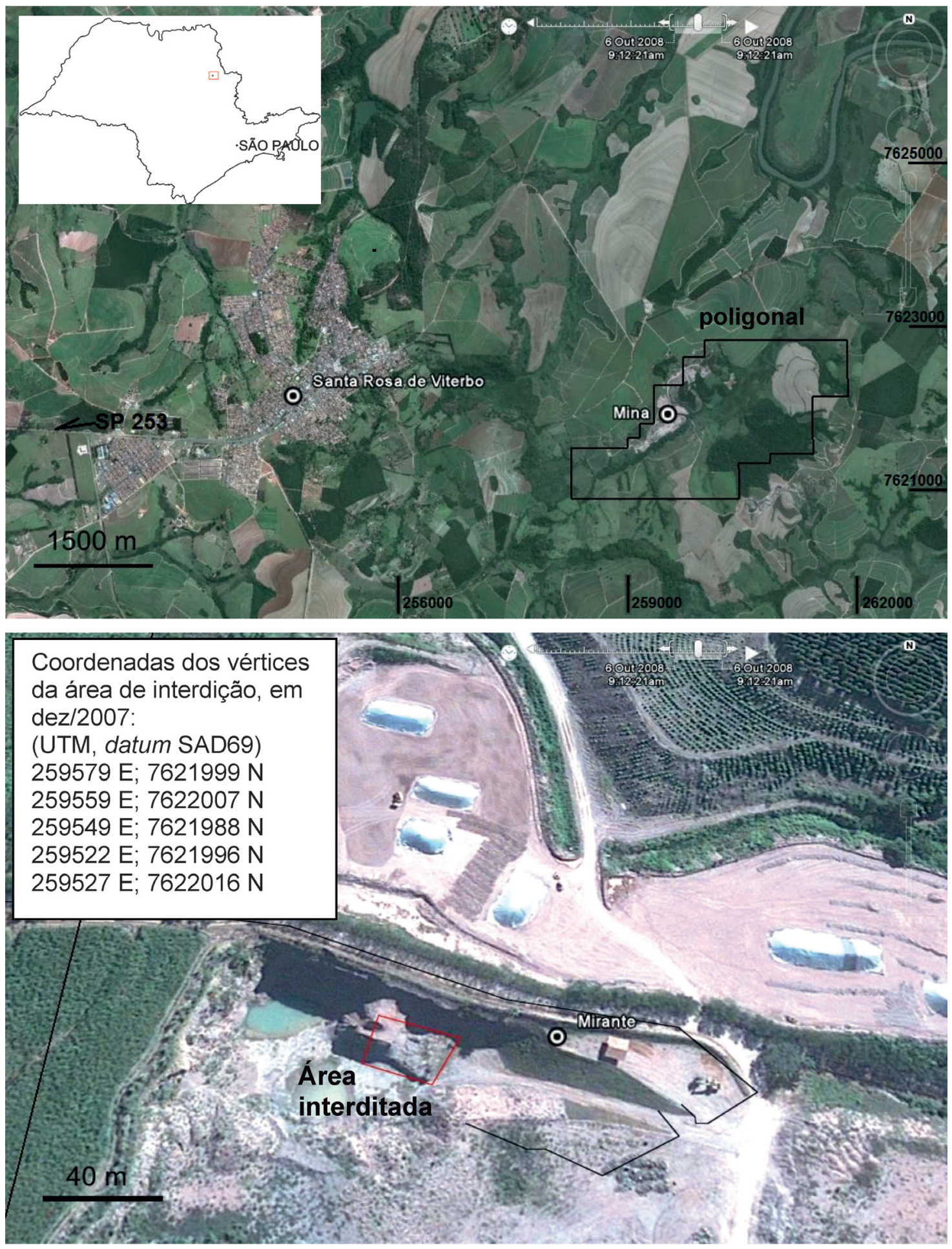

FIGURA 3 - Localização da Mina de Santa Rosa de Viterbo e do Sítio Paleontológico. Acima: poligonal minerária da empresa PH7 Mineração de Calcário Ltda. Abaixo: detalhe da figura anterior, com localização da área interditada em dezembro/2007 (em vermelho). Imagens de satélite obtidas do Google Earth. 

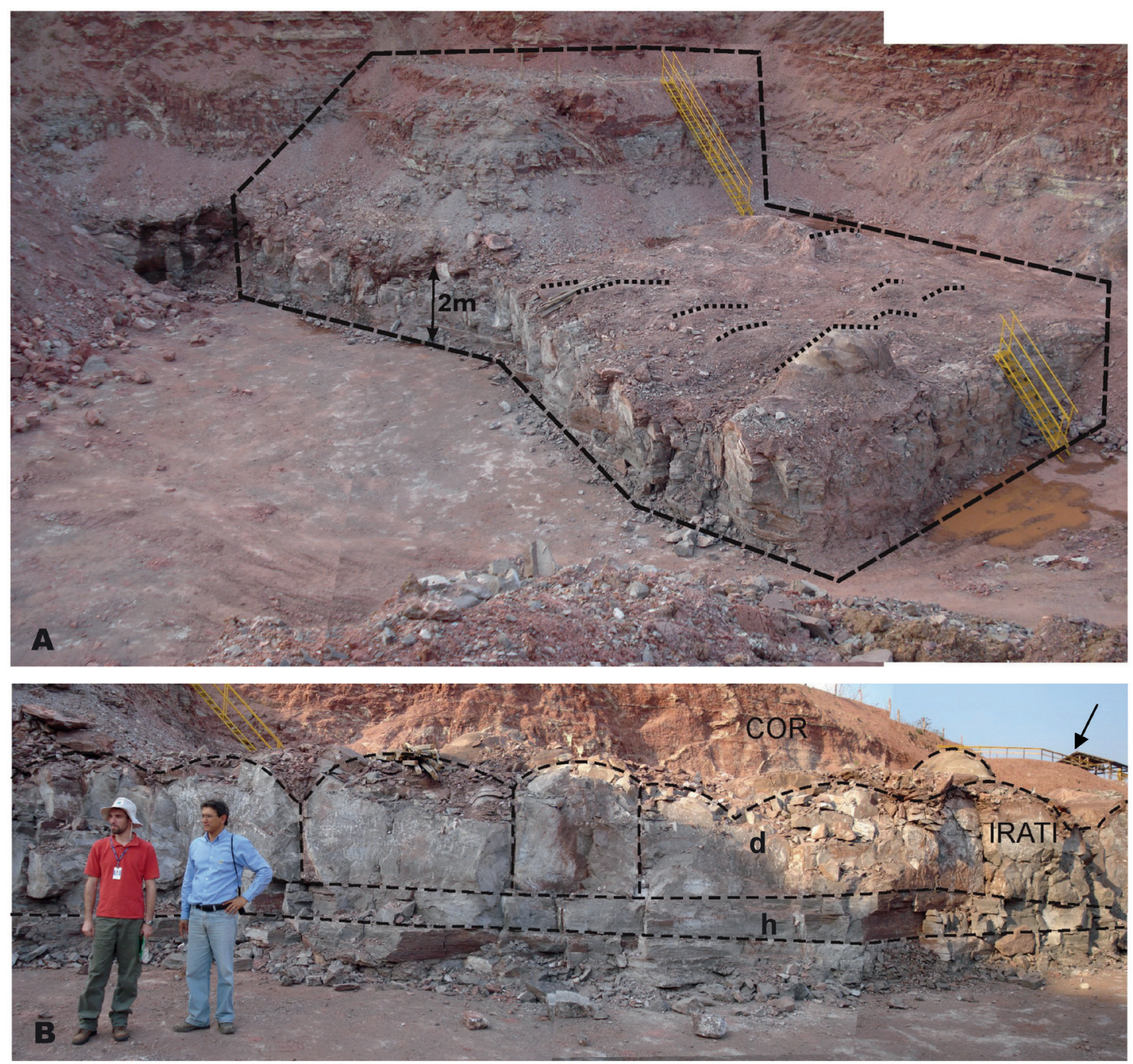

FIGURA 4 - Vista geral do Sítio Paleontológico da Mina de Santa Rosa de Viterbo - área protegida por interdição do DNPM. A: Área interditada (limite aproximado tracejado), com escadas de acesso aos diferentes níveis do Sítio. Domos alongados ressaltados pelo pontilhado. B: Porção frontal da área interditada com detalhes dos estromatólitos dômicos (d) sobrepostos a esteiras estromatolíticas (h). Siltitos da Formação Corumbataí (COR) sobrepõem calcários estromatolíticos do Subgrupo Irati. Centro de visitação e mirante no canto superior direito (seta).

ressados, como o setor público, o segmento produtivo e a comunidade geocientífica.

A iniciativa da empresa concessionária ( $\mathrm{PH} 7$ Mineração de Calcário Ltda.) na manutenção das medidas de proteção do sítio paleontológico de Santa Rosa de Viterbo é um exemplo a ser seguido por outros empresários do segmento da Mineração. Mostra que é viável conciliar mineração e geoconservação.

\section{AGRADECIMENTOS}

Este artigo foi elaborado por ocasião da conclusão do Curso de Especialização em Gestão e Política Mineral, ministrado pela Universidade do Sul de Santa Catarina - UNISUL, promovido pelo Ministério de Minas e Energia (MME) e pelo DNPM, por meio do Projeto ESTAL (Assistência Técnica ao Setor de Energia do MME). O trabalho contou com a orientação da Profa. Dra. Eliane Del Lama (IGc-USP), a quem os autores agradecem as correções e sugestões de melhoria do texto. Os trabalhos de campo no interior paulista contaram com a colaboração dos colegas paleontólogos do DNPM, Irma Tie Yamamoto e Rodrigo da Rocha Machado (Museu de Ciências da Terra - MCT/DNPM/RJ). Os autores agradecem também às sugestões dos dois revisores da Revista. 


\section{REFERÊNCIAS BIBLIOGRÁFICAS}

AWARAMIK, S.M. 1971. Precambrian Columnar Stromatolite Diversity: reflection of Metazoan Appearance. Science, 174: 825-827.

BRILHA, J. 2005. Património Geológico e Geoconservação: A conservação da Natureza na sua vertente geológica. Braga, Palimage Editores, $190 \mathrm{p}$.

DELPHIM, C.F.de M. 2009. Patrimônio Cultural e Geoparque. Geologia USP, Publicação Especial, 5:75-83.

DNPM - DEPARTAMENTO NACIONAL DE PRODUÇÃO MINERAL. 2010. Parecer N ${ }^{\circ}$ 107/2010/FM/PROGE/DNPM. Atribuições do DNPM em matéria de fósseis e sítios de valor paleontológico encontrados no território brasileiro. Documento inédito. Disponível em http://www.dnpm.gov.br/mostra_arquivo.asp?IDBancoArquivoArquivo=4106. Acessado em 27/dez./2011.

GUTIÉRREZ-MARCO, J.C.; SÁ, A.A.; BELLIDO, D.C.; RÁBANO, I; VALÉRIO, M. 2009. Giant trilobites and trilobite clusters from the Ordovician of Portugal. Geology, 37(5): 443-446.

HACHIRO, J. 1996. O Subgrupo Irati (Neopermiano) da Bacia do Paraná. Instituto de Geociências, Universidade de São Paulo, Tese de Doutoramento, $196 \mathrm{p}$.

HACHIRO, J.; COIMBRA, A.M. 1992. Bone beds e Shell beds como feições diagnósticas de tempestitos da Formação Irati no Estado de São Paulo. In: SBG, CONGRESSO BRASILEIRO DE GEOLOGIA, 37, São Paulo, Boletim de Resumos Expandidos, 2: 511-512.

HERZOG, A.; SALES, A.; HILMER, G. 2008. The UNESCO Araripe Geopark: a short story of the evolution of life, rocks and continents. Fortaleza, CE, Expressão Grafica e Editora, 71 p.
KNOLL, A.H. 1990. Precambrian evolution of Procariotes ans Protists. In: D.E.G. Briggs \& P.R. Crowther (Eds.) Palaeobiology: a synthesis, Oxford, Blackwell Science, p. 9-16.

RICARDI-BRANCO, F; CAIRES, E.T.; SILVA, A.M. 2009. Campo de estromatólitos gigantes de Santa Rosa de Viterbo, SP: excelente registro do litoral do Mar Permiano Irati, Bacia do Paraná, Brasil. In: M. Winge, C. Schobbenhaus, C.R.G. Souza, A.C.S. Fernandes, M.L.C. Berbert-Born, E.T. Queiroz, D.A. Campos (Eds.) Sítios Geológicos e Paleontológicos do Brasil. Brasília, CPRM, v. 2, p. 371-380.

SCHOBBENHAUS, C.; CAMPOS, D.A.; QUEIROZ, E.T.; WINGE, M.; BERBERT-BORN, M.L.C. (eds.) 2002. Sítios Geológicos e Paleontológicos do Brasil. Brasília, DNPM, v. 1, 554 p.

SCHOBBENHAUS, C. \& SILVA, C.R. 2010. O papel indutor do Serviço Geológico do Brasil na criação de Geoparques. Brasília, CPRM, 22 p. Disponível em http://www.cprm.gov. br/publique/ media/schobbenhaus_Silva $\% 20$ _2010.pdf. Acessado em 17/fev./2012.

UNESCO - Organização das Nações Unidas para a Educação, a Ciência e a Cultura. 2008. Guidelines and criteria for National Geoparks seeking UNESCO's assistance to join the Global Geoparks Network. Paris, França. Disponível em http://www.unesco.org/science/ earth/doc/ geopark/2008guidelinesJuneendors ed.pdf. Acessado em: 25/ago./2010.

WINGE, M.; SCHOBBENHAUS, C.; SOUZA, C.R.G.; FERNANDES, A.C.S.; BERBERT-BORN, M.L.C.; QUEIROZ, E.T.; CAMPOS, D.A. (eds.) 2009. Sítios Geológicos e Paleontológicos do Brasil. Brasília, CPRM, v. 2, 516 p.

ZOUROS, N. 2004. The European Geoparks Network, Geological heritage protection and local development. Episodes, 27(3): 165-171.

Endereço dos autores:

Ana Lúcia Desenzi Gesicki - Departamento Nacional de Produção Mineral, Superintendência de São Paulo (DNPM/SP), Rua Loefgreen, 2225, CEP 04040-033, São Paulo, SP. E-mail: ana.gesicki@dnpm.gov.br

Rodrigo Miloni Santucci - Universidade de Brasília - UnB, Campus Planaltina, Faculdade UnB Planaltina - FUP, Área Universitária n. 1, Vila Nossa Senhora de Fátima, CEP 73345-010, Brasília, DF. E-mail: rodrigoms@unb.br 